\title{
Resenhas
}

\section{Edward P. Thompson: história e formação}

\author{
Autores: Liane Maria Bertucci, \\ Luciano Mendes de Faria Filho, \\ Marcus Aurélio Taborda de Oliveira \\ Cidade: Belo Horizonte - MG \\ Editora: UFMG
}

Ano: 2010

Partindo do pressuposto de que a produção de Edward Palmer Thompson pode ajudar, de inúmeras maneiras, a "indagar o fenômeno educacional" na contemporaneidade (p. 10), e de que pouco se recorre às obras deste historiador para pensar a história da educação no Brasil, o livro procura desenvolver uma reflexão sobre a educação, a escolarização e a sua história.

Cabe ressaltar a inserção acadêmica no âmbito da história da educação dos três autores do livro e o diálogo com as obras de Thompson em seus trabalhos. Liane Maria Bertucci é doutora em história pela Universidade Estadual de Campinas e professora de história da educação na Universidade Federal do Paraná; Luciano Mendes de Faria Filho é doutor em educação pela Universidade de São Paulo e professor de história da educação na Universidade Federal de Minas Gerais; e Marcus Aurélio Taborda de Oliveira é doutor em educação pela Pontifícia Universidade Católica de São Paulo e professor do programa de pós-graduação em história da educação e em lazer, na Universidade Federal de Minas Gerais.

O livro é dividido em três capítulos. Neles os autores dialogam com as contribuições de Thompson como historiador, com as noções-chave de cultura e experiência, para pensar a escolarização, e com a noção de "fazer-se", construída pelo autor a partir do estudo da classe operária inglesa, a qual se mostra como possibilidade para pensar a cultura escolar.

Assim, no primeiro capítulo, intitulado "Thompson historiador: Teoria, método e fontes - contribuições para a história da educação", o leitor tem acesso a "[...] um quadro de possibilidades de Thompson para pensar a produção do conhecimento histórico, seja na educação ou não [...]" (p. 13). Já no segundo capítulo, "Experiência e cultura em Thompson: Contribuições para uma história social da escolarização", o 
leitor encontrará a problematização do processo de escolarização como “[...] experiência histórica ainda aberta, e não predefinida [...]" (p. 13). E por fim, no terceiro capítulo, "Formação como fazer-se, um legado Thompsoniano: Contribuições para a educação", o livro se volta para a compreensão das formas como a escolarização

[...] pode produzir um sujeito que é, de alguma maneira, formado [...] para perpetuar a sociedade, ao mesmo tempo que adquire uma base cultural que permite produzir as condições de resistência a essa mesma sociedade $[\ldots]$ (p. 14).

Nos três capítulos, é realizado um diálogo com autores importantes do campo historiográfico, como Peter Burke, Eric Hobsbawm, Marc Bloch, Lucien Febvre e Carlo Ginzburg, assim como com autores que problematizam os currículos e as culturas escolares, a exemplo de Osmar Fávero, Ivor Goodson, Maria do Carmo Martins, André Petitat, Fernando Alvarez-Uria, Julia Varela e Diana Gonçalves Vidal. Há também o diálogo com outros dois importantes autores, principalmente em se tratando das noções de cultura e experiência: Raymond Williams e Walter Benjamin. Dentre as treze obras e textos de Thompson abordados no decorrer do livro, podem ser destacados: "A miséria da teoria" (1981), "A formação da classe operária inglesa" (1987), "Costumes em comum" (1998) e "Folclore, antropologia e história social" (2001).

Ao fim dos capítulos, os autores apresentam um conjunto de trabalhos publicados no Brasil sobre Edward Palmer Thompson e sua produção historiográfica. Vale destacar a importância desta iniciativa para o aprofundamento do debate para aqueles que se interessarem pelas contribuições desse historiador para a pesquisa em educação.

Os autores começam a discussão lançando as seguintes perguntas: “é possível pensar na possibilidade de um Thompson educador? Se sim, em que sentido" (p. 10)? Tomando o cuidado necessário de não "pedagogizar" o historiador, como os próprios autores ressaltam, com o "[...] intuito de preservar o contexto que viu nascer determinado conjunto de reflexões motivadas por um inventário muito particular de problemas [...]” (p. 10), há um reconhecimento de que várias são as possibilidades para se pensar o fenômeno educacional e os processos de escolarização por meio do legado de Thompson, destacando-se o que os autores consideram como duas das noções-chave de seu pensamento: a de cultura e a de experiência.

Essas noções, trabalhadas pelo historiador, permitem um alargamento da própria noção de formação, o que de fato, torna-se uma grande 
contribuição deste livro. Os autores destacam uma ideia bastante defendida por Thompson, de que os diversos sujeitos se formam e se educam " [...] nas mais diversas circunstâncias em que vivem, seja no mundo do trabalho, da família, da comunidade de pares, do lazer, entre muitos outros [...]" (p. 11). Nesta perspectiva, Thompson procurou demonstrar, utilizandose de seus estudos sobre a classe operária inglesa, que as pessoas se autorreconhecem como um grupo com interesses próprios, a partir de suas lutas cotidianas, costumes, leis, práticas religiosas, entre outras.

Interessante destacar que o entendimento da formação para além dos limites da escola torna-se fundamental para a compreensão da própria cultura escolar e dos processos de escolarização, permitindo, assim, a ampliação do olhar sobre o fenômeno educacional. Este entendimento demonstra também a necessidade de se ampliar os olhares acerca dos próprios sujeitos, aspecto bem abordado pelos autores ao se referirem à noção de experiência de Thompson e à sua preocupação em estudar a vida cotidiana de homens e mulheres simples (p. 22). Recusando a superioridade do econômico sobre o sociocultural, o historiador questiona como uma abordagem exclusivamente economicista compreenderia aspectos desse cotidiano, como "[...] os ritmos habituais de trabalho e lazer (ou festas), [...] os ritmos intrínsecos ao próprio ato de produzir [...]", as diversas crenças religiosas, entre outras formas de experiência humana (p. 28).

A própria consideração de Thompson sobre a amplitude das fontes e dos problemas torna-se de grande relevância para se pensar as questões propostas pelo livro. Como apontam os autores (p. 35):

[...] o fazer histórico de Thompson é um permanente questionar de nossa compreensão sobre o que considerar documento para o estudo histórico da escola e dos processos educacionais. Da legislação, tradicional, locus de pesquisa dos estudos da área, aos jornais diários de uma cidade, a gama de fontes e a forma de interrogá-las ganham nova perspectiva: aquela que aponta para a necessidade imperiosa de se perceber as relações e tensões sociais que um documento expressa; as marcas muitas vezes sutis das derrotas, as exuberantes expressões das vitórias dos que viveram e lutaram para construir a vida em sociedade.

O trecho final da citação revela um aspecto importante ressaltado pelos autores em outro momento do livro, quando relatam o que, segundo eles, seria uma grande lição deixada por Thompson: “[...] toda regulamentação da vida em sociedade é marcada por conflitos, cuja intensidade deve ser analisada nos termos de quem as viveu [...]" (p. 43). 
Assim, uma importante contribuição de Edward Thompson pode ser pensada em qualquer processo de formação. Ao propor que a história não é predeterminada, considerando a ação criativa dos homens e mulheres, contribui para pensar a escola, na medida em que aponta que sua ação não ocorre em um "vazio cultural". Apropriando-se das ideias do historiador, os autores observam que a escola, ao se estruturar como instituição, age "[...] numa situação de grande densidade cultural, na qual as pessoas são produzidas e reconhecidas como sujeitos na e da cultura [...]", sendo preciso reconhecer, assim, “[...] que o processo educativo posto em ação na e pela escola entra em tensão com processos educativos já existentes [...]” (p. 46).

Ao abordarem essa densidade cultural, os autores chamam a atenção para os processos históricos que constituíram e constituem a instituição escolar e a escolarização, também culturais, assim como as suas estratégias formativas. Como exemplo, citam a mobilização da sociedade a favor da escola, empreendida pela elite letrada, por meio da qual "[...] as culturas dos pobres e do aprendizado na e pela experiência deveriam ser abandonadas a favor das racionalizadas e racionalizadoras culturas escolares [...]" (p. 47).

Os autores ressaltam, assim, que a emergência da escola criou novas formas e padrões de socialização, que tendiam a " “...] afastar as novas gerações, sobretudo das camadas mais pobres, da cultura cultivada pelos ancestrais [...]" (p. 52); interrogam "[...] as formas pelas quais os tempos escolares vão ganhando legitimidade e provocando um crescente tensionamento do conjunto dos tempos sociais [...]" (p. 61). Chamam a atenção, desta forma, para um longo percurso que precisa ser estudado, dando destaque ao modo como instituições sociais

“[...] vão inventando ou desautorizando tradições culturais e políticas as mais diversas, e sobre as formas como as escolas são chamadas a contribuir com a formação cívica e, por que não, com a espetacularização da política [...]” (p. 61).

Com estas reflexões, o livro contribui para pensar novas possibilidades de pesquisa na história da educação e também para desnaturalizar a instituição escolar e os próprios processos de escolarização, inseridos em diferentes contextos históricos, marcados por inquietações de um tempo específico. Traz elementos também para pensar as dimensões da formação como "intimamente relacionadas ao conjunto das experiências dos sujeitos" (p. 52), uma das grandes possibilidades oferecidas pelos 
trabalhos de Thompson para pensar os estudos em educação. A noção de experiência, cunhada pelo historiador, implica o reconhecimento dos sujeitos como reflexivos, capazes de, em suas ações, construírem continuamente o movimento da história (p. 49).

E, no entendimento de uma educação que se faz nas relações sociais e que extrapola os limites da escola e da sala de aula, dimensão fundamental para a compreensão da própria instituição escolar, os autores retomam a ideia Thompsoniana de "fazer-se", ou seja, os indivíduos são sujeitos de sua própria formação, de um processo que permite a ideia de emancipação (p. 66). Como observam os autores, fala-se de homens e mulheres, "[...] em sua vida material, em suas relações determinadas, em sua experiência dessas relações, e em sua autoconsciência dessa experiência [...]" (p. 69).

Assim, outra importante contribuição é trazida pelo livro a partir das ideias de Edward Palmer Thompson: as diferentes formas de reação dos agentes, no caso os escolares, que precisam ser reconhecidas não como adesão cega às intervenções de diversas instâncias normatizadoras, mas como diálogo. Priorizando a experiência do indivíduo, que, como já referido, não se encontra em "um vazio cultural", o diálogo "[...] deve considerar tanto a dimensão racional quanto a dimensão sensível postas em prática no ato de formação [...]” (p. 71). A experiência consistiria, assim, em um elemento mediador, uma conexão entre processo histórico, determinações culturais e ação humana individual, em permanente tensão.

Entre a determinação e a apropriação, entre a estrutura e o processo, entre a singularidade e a generalização, medeia a experiência. Logo, esse autor não descartaria uma análise ideológica da cultura, mas não a reduziria também à lógica da conspiração, leitura que marca ainda hoje grande parte dos trabalhos em educação no Brasil. Ao propor a dialética entre educação e experiência o autor caracteriza o segundo termo como uma "exploração aberta do mundo de nós mesmos" (p. 80).

Desta forma, experiência é compreendida pelos autores como “[...] própria de indivíduos singulares e é incompatível com os cálculos que reduz homens e mulheres a insumos [...]". Ela é dialógica e "[...] se funda no ser sensível, que está em tensão permanente com as estruturas econômicas, políticas e sociais sintetizadas na cultura [...]" (p. 84).

Finalizando, o livro sugere a importância de considerar a tensão entre formas de dominação e resistência, fundamental para se pensar a escola e a escolarização, já que "[...] os indivíduos são partícipes dessa luta, por adesão ou omissão, resistência ou conformação, mas o são em 
situação [...]" (p. 91). Os autores problematizam as possibilidades de formação postas pelo mundo contemporâneo, pautadas pelas ideias de autoconsciência crítica, autodeterminação, autonomia, reciprocidade e mutualismo, que remetem à noção de autoformação trabalhada por Thompson, mas que ainda contrastam com um mundo que parece

[...] marcado pela heteronomia, pela indiferença, pela atualização sem precedentes das formas de dominação, seja pela força das armas ou pela educação dos sentidos, ou simplesmente pela negação do direito à dignidade a grandes contingentes da população mundial [...] (p. 92).

E, assim, concluem que a formação, "[...] entendida como processo de autorreflexão, de autoconhecimento, de contínuo fazer-se, inclusive escolar, teria um lugar fundamental para que a sociedade pudesse se organizar em outras bases [...]" (p. 93).

Nesse sentido, o livro cumpre o objetivo proposto e revela grandes contribuições para pensar a educação e a escolarização na contemporaneidade, a partir dos estudos do historiador Edward Palmer Thompson. A ideia de formação como um contínuo "fazer-se", as noções de cultura e experiência e de educação para além do limite escolar podem possibilitar novos olhares para a própria escola e para os sujeitos que dela fazem parte, assim como para as tensões de uma cultura sempre em movimento, que não abarca apenas perspectivas de conformação, mas, como lembram os autores, possibilidades de reinvenção.

Sarah Teixeira Soutto Mayor

Mestre em Estudos do Lazer pela Universidade Federal de Minas Gerais (UFMG). Integrante do NUPES/UFMG (Núcleo de Pesquisas sobre a Educação dos Sentidos e das Sensibilidades), e do CEMEF/UFMG (Centro de Memória da Educação Física, do Esporte e do Lazer).

Endereço para correspondência: Rua Paulo Piedade Campos, 300/102

Estoril

Belo Horizonte - MG

CEP: 30494-225

E-mail: sarahtsouttomayor@hotmail.com

Recebido em: 21 out. 2011

Aprovado em: 25 jan. 2012 